\title{
Which pigment appears first in the corolla- patterned or background?
}

Eapsa Berry ( $\nabla$ eapsa321@gmail.com )

University of Delhi https://orcid.org/0000-0001-7089-7157

R. Geeta

University of Delhi https://orcid.org/0000-0002-8498-470X

\section{Short Report}

Keywords: background pigment, corolla, development, morphogenesis, pigment pattern, timing

Posted Date: January 21st, 2022

DOI: https://doi.org/10.21203/rs.3.rs-1118106/v1

License: (9) This work is licensed under a Creative Commons Attribution 4.0 International License. Read Full License 
2 Which pigment appears first in the corolla—patterned or background?

3

4

5

6

7

$$
\text { Eapsa Berry }{ }^{1} \text { and R. Geeta }{ }^{1 *}
$$

${ }^{1}$ Department of Botany, University of Delhi, Delhi 110007, India

*Corresponding author

E-mail: rgeeta53@gmail.com 


\section{MAIN CONCLUSION}

We show that background and patterned pigmentation on corolla can appear either

simultaneously or successively with the predominance of the case of pigment pattern developing earlier than background pigmentation.

\section{ABSTRACT}

Flowers display a diversity of pigment patterns on petals - spots, stripes, blotches, and varying combinations of these. Such pigment patterns are accompanied and surrounded by a background that is a contrasting shade or colour sometimes white. We ask the question: Do the pattern and background colours appear simultaneously or successively, and if the latter, is there a bias in which one appears first? We studied the morphological development of flowers of 35 species containing both types of pigmentation, sampled from clades across angiosperms (monocots, Ranunculales, Caryophyllales, rosids and asterids) to address this question of timing of occurrence of the two types of pigmentation. In 28 of the species studied, pigment pattern started appearing in the corolla earlier than the background colour. Pigment pattern appeared later in four cases, and simultaneously with background colour in three cases. Thus, our results reveal, for the first time, variation in developmental sequence of pattern and background colour, with an apparent tendency toward earlier appearance of pigment pattern in the corolla. We hypothesize that the mechanisms involve the imperatives of pigment types, reaction kinetics, differential gene expression, and reaction-diffusion models.

\section{KEY WORDS}

background pigment, corolla, development, morphogenesis, pigment pattern, timing 
In angiosperms, flowers, more than any other organ, display a large variety of pigment patterns. Floral colour patterns are localized in clearly confined and generally welldefined areas on the corolla to form dots, streaks, and blotches (Wheldale-Onslow 1925;

Fig. 1). Such pigment patterns are present on, or are surrounded by, a background of either contrasting colour or contrasting shade of a similar colour or on a non-pigmented background. Pigment patterns usually, though not always, are more intensely coloured than the background. In some flowers, pigment patterns develop in distinct regions of the corolla (e.g., petal lobe, throat region, veins), while in others, the area of pigment pattern is not well-defined, resulting in blurred boundaries (Drews et al. 1992). Pigments occur mostly in the adaxial epidermal cells of petals, but sometimes in both abaxial and adaxial epidermal cells (Kay et al. 1981) Pigment synthesis is initiated at very early stages of the bud, as observed in Antirrhinum majus L. (Plantaginaceae), Petunia hybrida E.Vilm. (Solanaceae) and Gorteria diffusa Thunb. (Asteraceae) (Coen et al. 1986; Martin and Gerats, 1993; Thomas et al. 2009). Petal development can be broadly divided into two phases: cell division (slow growth) and cell expansion (fast growth) with duration of the phases varying from species to species (Martin and Gerats, 1993; Weng et al. 2011; Landis et al. 2016) Pigment formation starts when the petal enters the second phase, but regulatory gene expression is maximum in the final stages of the first phase (Coen et al. 1986; Martin and Gerats, 1993)

A pigment pattern on the corolla, both in its presence and localization or design, is generally a stable, heritable trait that appears consistently in succeeding generations, with its appearance governed by genes, its shape being either regular (geometric) or irregular. 
Pigment patterns other than stable, heritable patterns also exist - e.g., colour break patterns (Hunter et al. 2011) but are not the subject of this study. There are various types of pigment patterns on corolla (Fig. 1), and the major types are streaks, spots, and blotch/es (Wheldale-Onslow, 1925; pers. obs.).

It is known that the expression of pigments (anthocyanins, carotenoids, betalains, chlorophylls) are regulated by R2R3-MYB transcription factors (TF) (Stracke et al. 2001, Hatlestad et al. 2015; Sagawa et al. 2016; Ampomah-Dwamena et al. 2019) In the model plant, Arabidopsis thaliana (L.) Heynh., anthocyanin pigmentation is regulated by subgroup 6 members of the R2R3-MYB TF family by interacting with bHLH TF and WD repeat proteins (Walker et al. 1999; Stracke et al. 2001; Matsui et al. 2004; Gonzalez et al. 2008; Dubos et al. 2010) The regulatory complex of R2R3-MYB, bHLH, and WD40 interact to bring about anthocyanin pigmentation and patterning in flowers, fruits, seeds, and leaves in Zea mays L. (Poaceae), Antirrhinum majus L., Petunia hybrid Juss., Mimulus gattatus L. (Phrymaceae), and Ipomoea nil L. (Convolvulceae) (Ramsay \& Glover, 2005, Davies et al. 2012). Various studies suggest that R2R3-MYB genes are the primary activators of pigments biosynthesis in petals (Elomaa et al. 2003; Morita et al. 2006; Schwinn et al. 2006; Nakatsuka et al. 2008; Chiou and Yeh, 2008; Ma et al. 2009; Shang et al. 2010; Yamagishi et al. 2010; Albert et al. 2011; Ohno et al. 2011; Yuan et al. 2014; Sagawa et al. 2016) and that R3-MYB genes act as repressors (Ding et al 2020, Zang et al. 2020) The morphogenesis of colour patterns is based on the regulated spatiotemporal expression of R2R3-MYB, bHLH, and WD40 TF genes (Schwinn et al. 2006). Post-transcriptional regulation by small RNAs has also been indicated in pigment biosynthesis in flowers (Davies et al. 2012). Apart from MYB and bHLH regulators, 
RNA interference and microRNA (miRNA) based regulation also affect pigment patterns

79 (Matsubara et al. 2012).

The purpose of this study was to understand one aspect of the development of corolla pigment patterns (CPP) in angiosperms. The main question addressed in this study: Is the emergence of the two types of pigmentation on the developing petal (background and patterned) simultaneous or successive?

\section{MATERIALS AND METHODS}

\section{Morphological developmental study}

A survey of morphological development of CPP and background pigmentation was done on 35 plant taxa sampled across angiosperm (Fig. 2). Care was taken to have as broad sampling as possible across the angiosperms, given limitations of availability. We have included monocots, Ranunculales, and core-eudicots -- Malvidae (rosid II) and Fabidae (rosid I), Caryophyllales, and seven families from asterids - asterid I (six families) and asterid II (one). All were cultivated species, most of which were growing in the Botanical Garden of the Department of Botany, University of Delhi, Delhi, India, and some in the university compound of Universidad Nacional Autónoma de México, México City, Mexico. The morphological development, from genesis to maturity, of pigment pattern and background pigment was observed, recorded, and analyzed.

Floral buds of different sizes and developmental stages based on pigment development were harvested from 3-4 plants of each species. The buds for each species were arranged in order of increasing size and/or advancing stage. The corollas of flowers at different 
developmental stages were split open and placed on a contrasting background, and their images captured. Small buds $<5 \mathrm{~mm}$ in length were photographed under a stereo microscope (Zeiss Stemi 305). The younger the bud, the more difficult it was to flatten the corolla and the use of a drop of tap water and paint brush (size ' 0 ') allowed easy flattening and smoothening of petals on glass slides. Sometimes glass plates were placed on the petals to hold them down; and sometimes additional plasticine clay support was given to flatten the curled petals. Most images were captured by Nikon D200 or D5100.

To illustrate the phylogenetic distribution of the sampled species, a phylogenetic tree based on APG IV system of classification (Stevens P. F. 2001 onwards) was drawn in Mesquite 3.5 (Maddison and Maddison, 2015) and edited in FigTree v. 1.4 (Rambaut, 2009).

\section{Estimation of the relative percentage of flowers with both background and patterned}

\section{pigmentation}

In order to estimate the frequency of flowers with background and patterned pigmentation across angiosperms, we investigated a sample of 525 flowering plant species, from the dataset of Soltis et al. 2011, in which the sampling is assumed to have been random with reference to pigmentation type. We scored the presence and absence of background pigmentation and/or pigment patterns by observing photographs of flowers from online databases. Using the scored data, the proportion and percentage of flowers with both background and patterned pigmentation was estimated. While white colour of plant tissue is said to be due to the total reflection of light in the absence of pigment (Peach, 1955), these tissues may include UV-reflecting or absorbing areas visible to pollinators, but we did not 
121 include flowers with CPP on human-white background in our study as we were interested in

122 pigment development.

\section{RESULTS AND DISCUSSION}

124 The sequence of appearance of CPP and background pigmentation was observed and recorded for 35 species (Fig. 3, Supplementary Table S1). Pigment pattern was found to start developing first, and the background pigment appeared later in corollas of 28 of the 35 species examined. In four species background pigmentation appeared earlier, while in the remaining three species patterned and background pigmentation appeared simultaneously. In general, for both CPP and background, pigmentation first appeared in the central part of the future total pigmented area of the petal, irrespective of whether it was restricted to the proximal, distal, or central region on the petal. Pigment development was divided into two categories with respect to the mode of localization: on-vein and off-vein ('off-vein' referring to the inter-vein regions). In the on-vein category, the pigment starts developing exclusively on the epidermal regions above the veins and then spreads to include the off-vein epidermal regions of total pigmentation (e.g., Ruellia simplex C. Wright). On the other hand, in the offvein category, pigmentation starts first in the regions in between veins (e.g. Ruellia tuberosa L.; Supplementary Fig. S1). In both cases, the pigmentation starts from the central part of the total assignable area gradually developing to include more area in a centrifugal pattern maintaining an apparently uniform rate.

We observed that in all the four cases where the background pigment appeared first

(Canna indica L., Eschscholzia californica Cham., Caesalpinia pulcherrima (L.) Sw. and Tagetes tenuifolia Cav.), the pigment combination is yellow background with orange/red CPP (Fig. 2, Supplementary Table S1). pattern, we investigated 525 plant species in the study of Soltis et al. (2011). These species 
belong to 62 orders (of a total of 64) and 298 families (of 416) according to the APG IV system of classification (Chase et al. 2016). We found that 66 of the 525 species (less than $13 \%$ ) showed both background and patterned pigmentation. These 66 plant species belonged to 48 plant families in 22 plant orders, of which more than $50 \%$ representation was from the five eudicot plant orders Lamiales ( 8 families), Malpighiales (7 families), Asterales (3 families), Caryophyllales (3 families), Ericales (3 families) and Ranunculales (3 families) of the total of 62 orders in the study (see Supplementary Table S2 and Fig S2). Adding to this the number of species (41 spp.) with patterned pigmentation on white/colourless background, this makes up a total of 107 of 525 plant species that show patterned pigmentation. Most of the species in the angiosperm study $(\sim 80 \%)$ had flowers that were non-patterned, very small, or had no perianth. It is noteworthy that some clades appear to be consistently non-patterned (Supplementary Fig. S2). Our results suggest that our own observational study may be a reasonable representation of the development of flower pigmentation across angiosperms.

In our study, we found all possible sequences of development - CPP appearing first, i.e, before background pigmentation started (28 of 35 species); CPP appearing later than background pigmentation (four species); and both types of pigmentation appearing simultaneously (three species). This raises the following questions: (i) are there plausible processes that might underlie the preferred developmental sequence in a large proportion (80\%) of flowers observed; and (ii) are there features that distinguish the flowers of species that exhibit other developmental sequences; and (iii) could the sequence of pigment appearance in a species or taxon depend on the type of pigments involved? We consider these questions in the light of plausible underlying genetic, biochemical, and developmental factors that could explain the apparent general pattern and departures from this pattern that we observed. 
Early and late gene expression of pigmentation in flower development show temporal difference in expression of pigmentation of two types. In Clarkia gracilis A. Nelson \& J.F. Macbr. (Onagraceae), different copies of the dihydroflavonol reductase (DFR) gene are expressed at different stages of bud development and are expressed either in the CPP or in the background (Martins et al. 2013).

Intense and more pigmented anthocyanin patterned pigmentation appear earlier than lighter background pigmentation. In petals of Xibie tree peony (Paeonia spp., Paeoniaceae) the blotch regions (CPP) contain higher levels of anthocyanin compared to the background region, conferring a darker colour to blotches (Zhang et al. 2007). Deeper blue flowers of Torneia fournieri Lind. (Linderniaceae) are produced when anthocyanins make complexes of co-pigments with flavones or flavonols; in some cases the complexes are elaborate and consist of six anthocyanin and six flavone molecules and two metal ions (Goto and Kondo, 1991; Aida et al. 2000). It is likely that in most flowers there exist quantitative and qualitative differences in the sets of pigment molecules respectively in CPP and background regions. As most of the above pigments may be supposed to involve similar pigment biochemical pathway (e.g., flavonoid biosynthetic pathway: Martins et al. 2013), the kinetics of the reactions are likely to involve a rate-limiting step triggering controlled accumulation of

187 pigment biomolecules. For instance, in the flavonoid biosynthetic pathway, substrate competition between enzymes occurs to produce differences in the relative quantities of anthocyanins and flavonols resulting in different pigmentation outcomes (McCarthy et al. 2017, 2020). Therefore, one can speculate that, for the accumulation of relatively large quantities of the same pigment molecule (quantitative difference) or a greater variety of pigment molecules (qualitative difference), CPP development might have to start early 
enough to allow this accumulation well in time before the flower bud opens. The differential timing of expression would be regulated by TFs such as R2R3-MYB genes (Schwinn et al. 2006; Albert et al. 2011). The temporal and spatial separation of patterned and background pigmentation is governed by reaction-diffusion kinetics. Regulated by the interaction of R2R3-MYB and R3-MYB proteins, that corresponds to an activator-inhibitor system of reaction-diffusion model, spot patterns are formed in Mimulus flower petals (Ding et al. 2020).

Developmental timing of anthocyanin, chlorophyll, and carotenoid expression is different. In cases where background pigmentation appears either simultaneously with or earlier than patterned pigmentation, we suggest that this may occur in those instances where a) the background and patterned areas do not show significant differences in concentration of pigment molecules -- this type of pigmentation might not involve enzymatic competition, or b) entirely different classes of pigments occur in the two regions (e.g., anthocyanins and carotenoids). It has been observed that chlorophyll and anthocyanins express early in the time of flower development and carotenoids develop later in the development process (Xue at al., 2019). Carotenoids and anthocyanins have distinct biosynthetic pathways as well as sites of synthesis and occurrence. Carotenoids are known to be synthesized and stored in plastids (chromoplasts in flowers and fruit) (Sun et al. 2018), whereas anthocyanins are synthesized in the cytosol and get stored in vacuoles (Kitamura, 2006). The latter scenario is suggested by our observation that, in the four cases where the background pigment appeared first, there was yellow background with orange/red CPP, presumably involving carotenoids. This might reflect a limitation of our study due to inadequate sampling or, alternatively might prove an interesting pointer demanding further investigation. In the cases where the background pigmentation and the patterned pigmentation appear simultaneously, then there could be the following steps: i) flowers of 
218 different species show variable time duration of development in cell division and cell

219 elongation phases (Martin \& Gerats, 1993), therefore, sometimes the time periods of appearance coincide due to short cell elongation phase, ii) in short cell elongation phase mutually exclusive localizations of background and patterned pigmentation comprising of

222 different pigment molecules (with no substrate competition) appear simultaneously, e.g. Thunbergia erecta the blotch pigmentation is produced by carotenoids (yellow/orange) and the background is made up of anthocyanins and both appear simultaneously.

Deeper mechanistic insights would help understand the biology of corolla pigmentation and also yield information for horticulturists to experiment with CPP in closely related taxa for generating new hybrids or engineered flowers, e.g. roses with background pigmentation in general.

\section{CONCLUSIONS}

Not much is known about the modes of development of corolla pigmentation patterns in angiosperms. We show that all three conceivable modes of pigmentation development on corolla do occur, while equally significantly there is a strong case - of CPP developing earlier compared to background pigmentation - in favour of seeking various common underlying mechanisms. The present study is a small step toward better understanding of the evolution and development of CPP in angiosperms. 
241 The authors thank the garden staff of Department of Botany, DU including Aradhana

242 (garden in-charge), and gardeners Devender, Nizam, Ashok, and Jagdish. The authors are

243 grateful to Mark Olson for his guidance and National Autonomous University of Mexico

244 (UNAM) for giving the postdoctoral opportunity to EB where some part of the study was

245 done. The authors acknowledge support from R\&D grants of Delhi University (RG), and

246 a Research Fellowship of the University Grants Commission, Government of India (EB).

\section{AUTHOR CONTRIBUTIONS}

EB and RG contributed substantially and equally to each of the following: conception and design of the work, analysis and interpretation of results, and writing the manuscript; EB was responsible for acquiring the data. Each author has given final approval of the version to be sent for publication; and each has agreed to be accountable for all aspects of the work in order to ensure that questions related to the accuracy or integrity of any part of the work are appropriately investigated and resolved.

\section{DATA ACCESSIBILITY STATEMENT}

255
No data used in the study has been archived in public accessible repositories; all data related to the study has been fully described in the manuscript; and photographs of species not published are available on request.

\section{LITERATURE CITED}

Aida R, Yoshida K, Kondo T, Kishimoto S, Shibata M (2000) Copigmentation gives bluer flowers on transgenic plants with the antisense dihydroflavonol-4-reductase gene. Plant Sci 160:49-56 
Albert NW, Lewis DH, Zhang H, Schwinn KE, Jameson PE, Davies KM (2011) Members of an R2R3-MYB transcription factor family in Petunia are developmentally and environmentally regulated to control complex floral and vegetative pigmentation patterning. Plant J 65:771-784

Ampomah-Dwamena C, Thrimawithana AH, Dejnoprat S, Lewis D, Espley RV, Allan AC (2019) A kiwifruit (Actinidia deliciosa) R2R3-MYB transcription factor modulates chlorophyll and carotenoid accumulation. New Phyto 221:309-325

Barrier M, Robichaux RH, Purugganan MD (2001) Accelerated regulatory gene evolution in an adaptive radiation. Proc Natl Acad Sci 98:10208-10213

Chase MW, Christenhusz MJM, Fay MF, Byng JW, Judd WS, Soltis DE, Mabberley DJ, Sennikov AN, Soltis PS, Stevens PF (2016) An update of the Angiosperm Phylogeny Group classification for the orders and families of flowering plants: APG IV. Bot J Linn Soc 181:1-20

Chiou CY, Yeh KW (2008) Differential expression of MYB gene (OgMYB1) determines color patterning in floral tissue of Oncidium Gower Ramsey. Plant Mol Biol $66: 379-388$

Chiu LW, Zhou X, Burke S, Wu X, Prior RL, Li L (2010) The purple cauliflower arises from activation of a MYB transcription factor. Plant Physiol 154:1470-1480

Coen ES, Carpenter R, Martin C (1986) Transposable elements generate novel spatial patterns of gene expression in Antirrhinum majus. Cell 47:285-296

Davies KM, Albert NW, Schwin KE (2012) From landing lights to mimicry: the molecular regulation of flower colouration and mechanisms for pigmentation patterning. Funct Plant Biol 39:619-638

Demerec M (1935) Unstable genes. Bot Rev 1:233-248

Ding B, Patterson EL, Holalu SV, Li J, Johnson GA, Stanley LE, Greenlee AB, Peng F, Bradshaw Jr HD, Blinov ML, Blackman BK (2020) Two MYB proteins in a selforganizing activator-inhibitor system produce spotted pigmentation patterns. Curr Biol 30:802-814

Drews GN, Beals TP, Bui AQ, Goldberg RB (1992) Regional and cell-specific gene expression patterns during petal development. Plant Cell 4:1383

Dubos C, Stracke R, Grotewold E, Weisshaar B, Martin C, Lepiniec L (2010) MYB transcription factors in Arabidopsis. Trends Plant Sci 15:573-581 
Elomaa P, Uimari A, Mehto M, Albert VA, Laitinen RA, Teeri TH (2003) Activation of anthocyanin biosynthesis in Gerbera hybrid (Asteraceae) suggests conserved protein-protein and protein-promoter interactions between the anciently diverged monocots and eudicots. Plant Physiol 133:1831-1842

Gierer A, Meinhardt H (1972) A Theory of Biological Pattern Formation. Kybernetik $12: 30-39$

Gonzalez A, Zhao M, Leavitt JM, Lloyd AM (2008) Regulation of the anthocyanin biosynthetic pathway by the TTG1/bHLH/Myb transcriptional complex in Arabidopsis seedlings. Plant J 53:814-827

Goto T, Kondo T (1991) Structure and molecular stacking of anthocyanins-flower color variation. Angew Chem Int Ed 30:17-33Hatlestad GJ, Akhavan NA, Sunnadeniya RM, Elam L, Cargile S, Hembd A, Gonzalez A, McGrath JM, Lloyd AM (2015) The beet Y locus encodes an anthocyanin MYB-like protein that activates the betalain red pigment pathway. Nat Genet 47:92-96

Hunter DA, Fletcher JD, Davies KM, Zhang H (2011) Colour break in reverse bicolour daffodils is associated with the presence of Narcissus mosaic virus. Virol J 8:412

Kay QON, Daoud HS, Stirton CH (1981) Pigment distribution, light reflection and cell structure in petals. Bot J Linn Soc 83:57-83

Kitamura SA (2006) Transport of flavonoids: from cytosolic synthesis to vacuolar accumulation. In The science of flavonoids Springer, New York, NY, pp. 123-146

Kondo S, Miura T (2010) Reaction-diffusion model as a framework for understanding biological pattern formation. Science 329:1616-1620

Koski MH, Ashman TL (2014) Dissecting pollinator responses to a ubiquitous ultraviolet floral pattern in the wild. Funct Ecol 28:868-877

Kristofferson KB (1922) Studies on Mendelian factors in Aquilegia vulgaris. Hereditas $3: 178-190$

Landis JB, O'Toole RD, Ventura KL, Gitzendanner MA, Oppenheimer DG, Soltis D E, Soltis PS (2016) The phenotypic and genetic underpinnings of flower size in Polemoniaceae. Front Plant Sci 6:1144

Lin-Wang K, Bolitho K, Grafton K, Kortstee A, Karunairetnam S, McGhie TK, Espley RV, Hellens RP, Allan AC (2010) An R2R3 MYB transcription factor associated with regulation of the anthocyanin biosynthetic pathway in Rosaceae. BMC Plant Biol 10:50 
Ma H, Pooler M, Griesbach R (2009) Anthocyanin regulatory/structural gene expression in Phalaenopsis. J Am Soc Hortic Sci 134:88-96

Martin C, Gerats T (1993) Control of pigment biosynthesis genes during petal development. Plant Cell 5:1253-1264

Martins TR, Berg JJ, Blinka S, Rausher MD, Baum DA (2013) Precise spatio-temporal regulation of the anthocyanin biosynthetic pathway leads to petal spot formation in Clarkia gracilis (Onagraceae). New Phyto 197:958-969

Matsubara K, Kei S, Koizumi M, Kodama H, Ando T (2012) RNA silencing in white petunia flowers creates pigmentation patterns invisible to the human eye. J Plant Physiol 169:920-923

Matsui K, Tanaka H, Ohme-Takagi, M (2004) Suppression of the biosynthesis of proanthocyanidin in Arabidopsis by a chimeric PAP1 repressor. Plant Biotechnol J $2: 1-7$

Maddison WP, Maddison D (2015) Mesquite: a modular system for evolutionary analysis. Available at: http://mesquiteproject.org and accessed on January 10, 2018

McCarthy EW, Berardi AE, Smith SD, Litt A (2017) Related allopolyploids display distinct floral pigment profiles and transgressive pigments. Am J Bot 104:92-101

McCarthy EW, Landis JB, Kurti A, Lawhorn AJ, Litt A (2020) The Genetic Basis of Flower Color Differences in Nicotiana tabacum. In: Ivanov N., Sierro N., Peitsch M. (eds) The Tobacco Plant Genome. Compendium of Plant Genomes. Springer, pp 175-193

Morita Y, Saitoh M, Hoshino A, Nitasaka E, Iida S (2006) Isolation of cDNAs for R2R3MYB, bHLH and WDR transcriptional regulators and identification of $\mathrm{c}$ and ca mutations conferring white flowers in the Japanese morning glory. Plant Cell Physiol 47:457-470

Nakatsuka T, Haruta KS, Pitaksutheepong C, Abe Y, Kakizaki Y, Yamamoto K, Shimada N, Yamamura S, Nishihara M (2008) Identification and characterization of R2R3MYB and bHLH transcription factors regulating anthocyanin biosynthesis in gentian flowers. Plant Cell Physiol 49:1818-1829

Newton WCF (1929) The inheritance of flower colour in Papaver rhoeas and related forms. J Genet 21:389-404

Ohno S, Hosokawa M, Hoshino A, Kitamura Y, Morita Y, Park KII, Nakashima A, Deguchi A, Tatsuzawa F, Doi M (2011) A bHLH transcription factor, DvIVS, is 
involved in regulation of anthocyanin synthesis in dahlia (Dahlia variabilis) J Exp Bot 62:5105-5116

Paech K (1955) Colour development in flowers. Annu Rev Plant Physiol 6:273-298

Rambaut A (2009) FigTree: Tree figure drawing tool. Available at: http://tree.bio.ed.ac.uk/software/figtree/(accessed 12 January 2019)

Ramsay NA, Glover BJ (2005) MYB-bHLH-WD40 protein complex and the evolution of cellular diversity. Trends Plant Sci 10:63-70

Rogers KW, Schier AF (2011) Morphogen gradients: from generation to interpretation. Annu Rev Cell Dev Bio 27:377-407

Sagawa JM, Stanley LE, LaFountain AM, Frank HA, Liu C, Yuan YW (2016) An R2R3-MYB transcription factor regulates carotenoid pigmentation in Mimulus lewisii flowers. New Phyto 209:1049-1057

Schwinn K, Venail J, Shang Y, Mackay S, Alm V, Butelli E, Oyama R, Bailey P, Davies $\mathrm{K}$, Martin C (2006) A small family of MYB-regulatory genes controls floral pigmentation intensity and patterning in the genus Antirrhinum. Plant Cell $18: 831-851$

Shang YJ, Venail J, Mackay S, Bailey PC, Schwinn KE, Jameson PE, Martin CR, Davies KM (2010) The molecular basis for venation patterning of pigmentation and its effect on pollinator attraction in flowers of Antirrhinum. New Phyto 189:602-615

Soltis DE, Smith SA, Cellinese N, Wurdack KJ, Tank DC, Brockington SF, RefulioRodriguez NF, Walker JB, Moore MJ, Carlsward BS, et al. (2011) Angiosperm phylogeny: 17 genes, 640 taxa. Am J Bot 98:704-730

Stevens PF (2001) onwards. Angiosperm phylogeny website. Accessed on Jan 12, 2019. Available at: http://www.mobot.org/MOBOT/ research/Apweb/

Stracke R, Werber M, Weisshaar B (2001) The R2R3-MYB gene family in Arabidopsis thaliana. Curr Opin Plant Biol 4:447-456

Sun T, Yuan H, Cao H, Yazdani M, Tadmor Y, Li L (2018) Carotenoid Metabolism in Plants: The Role of Plastids. Mol Plant 11:58-74

Thomas MM, Rudall PJ, Ellis AG, Savolainen V, Glover BJ (2009) Development of a complex floral trait: The pollinator-attracting petal spots of the beetle daisy, Gorteria diffusa (Asteraceae). Am J Bot 96:2184-2196 
Turing AM (1952) The chemical basis of morphogeneis. Philos Tran R Soc of B Biol Sci $237: 37-72$

Walker AR, Davison PA, Bolognesi-Winfield AC, James CM, Srinivasan N, Blundell TL, Esch JJ, Marks MD, Gray JC (1999) The Transparent Testa Glabral locus, which regulates trichome differentiation and anthocyanin biosynthesis in Arabidopsis, encodes a WD40 repeat protein. Plant Cell 11:1337-1350

Wheldale-Onslow M (1925) The anthocyanin pigments of plants. pp. Cambridge University Press.

Yamagishi M, Shimoyamada Y, Nakatsuka T, Masuda K (2010) Two R2R3-MYB genes, homologs of petunia AN2, regulate anthocyanin biosyntheses in flower tepals, tepal spots and leaves of Asiatic hybrid lily. Plant Cell Physiol 51:463-474

Yuan YW, Sagawa JM, Frost L, Vela JP, Bradshaw Jr, HD (2014) Transcriptional control of floral anthocyanin pigmentation in monkey flowers (Mimulus) New Phyto 204:1013-1027

Zhang H, Gong J, Chen K, Yao W, Zhang B, Wang J, Tian S, Liu H, Wang Y, Liu Y, Du L (2020) A novel R3 MYB transcriptional repressor, MaMYBx, finely regulates anthocyanin biosynthesis in grape hyacinth. Plant Sci 298:110588

Zhang J, Wang L, Shu Q, Liu Z, Li C, Wei X, Tian, D (2007) Comparison of anthocyanins in non-blotches and blotches of the petals of Xibei tree peony. Sci Hortic 114:104-111

\section{SUPPORTING INFORMATION}

\section{Table S1. Description of the observed developmental order of background and} pattern pigmentation on corolla in the taxa studied.

Fig. S1 Figure illustrates two vein-related types of development of corolla pigment pattern in two species of $\mathbf{R u e l l i a}$. a, $\mathbf{c}, \mathbf{e}$, and $\mathbf{g}$ are images of $R$. simplex where $\mathbf{c}$ ( $1.4 \mathrm{~cm}$ bud), $\mathbf{e}(1.5 \mathrm{~cm}$ bud), and $\mathbf{g}$ ( $3 \mathrm{~cm}$ bud) show 'on-vein' blotch pattern development. Again, $\mathbf{b}, \mathbf{d}, \mathbf{f}$, and $\mathbf{h}$ are images of $R$. tuberosa where $\mathbf{f}(1.8 \mathrm{~cm}$ bud), and $\mathbf{h}$ ( $3 \mathrm{~cm}$ bud) show 'off-vein' blotch pattern development, whereas a bud of smaller size $\mathbf{d}(1.4 \mathrm{~cm})$ shows no pigmentation. In $R$. simplex pigment pattern emerges in stage II when the corolla elongates and appears outside the covered apical part of the calyx; in R. tuberosa pigmentation appears in stage III when corolla tube bulges and spreads - pigmentation occurs rapidly in the case of R. tuberosa 
Table S2. Scored data on pigment pattern and background pigmentation for $\mathbf{5 2 5}$ flowering plant species from the dataset of Soltis et al. 2011.

\section{Fig S2 Displaying taxa with pigmentation types on the Soltis et.al. (2011)} angiosperm phylogeny. Taxa showing presence of pigment pattern and background (non-white) pigmentation are marked with solid red circles, and taxa with pigment pattern on a white background are shown using red hollow circles

\section{FIGURE LEGENDS}

\section{Fig. 1 Illustration of the different forms of corolla pigment pattern:}

(a-m) stable pattern (n, o) unstable pattern (a) background colouration (e.g. ${ }^{\psi}$ Barleria prionitis; Acanthaceae) (b) spot pigmentation pattern (e.g. ${ }^{\psi}$ Rhododendron triflorum; Ericaceae) (c, d) streak pattern (e.g. ${ }^{\psi}$ Duranta erecta; Verbenaceae) (e) band pattern ( ${ }^{\Psi}$ Andrographis paniculata; Acanthaceae) (f) blotch pattern $\left({ }^{\Psi}\right.$ Rhododendron dalhousiae; Ericaceae) $(\mathbf{g}, \mathbf{h})$ composite pattern $\left({ }^{\psi}\right.$ Dicliptera paniculata and ${ }^{\psi}$ Justicia simplex; Acanthaceae) (i) picotee pattern [Aquilegia vulgaris; Ranunculaceae (Kristofferson 1922) and Papaver rhoeas; Papaveraceae (Newton 1929)] (j) colour tinge/flush (k) bud-blush pattern (e.g. ${ }^{\psi}$ Allamanda blanchetii; Apocynaceae) (l) bull's-eye pattern (whole flower) [e.g. Argentina anserine (Koski and Ashman, 2014)] (m) star pattern (whole flower) (e.g. ${ }^{\psi}$ Ipomea nil) (n) colour-break pattern leading to formation of bicolour flowers [e.g. in daffodils, tulips and lilies (Hunter et al. 2011)] (o-i, o-ii) chimeric pattern showing two distinct flowers from the same plant [e.g. Mirabilis jalapa; Nyctaginaceae (Demerec, 1935)] ${ }^{\psi}$ - pers. obs.

\section{Fig. 2 Taxa sampled}


Out of the 35 species studied 28 showed CPP development starting earlier than the background pigmentation; four taxa, that are marked with pink coloured branches, showed precedence of background pigmentation over CPP; and three taxa here marked with a blue branch had CPP and background pigmentation emerging simultaneously

Fig. 3 Stages in the development of CPP and background pigmentation in representative species

a-f Campsis radicans, Digitalis purpurea, Catharanthus roseus, Dianthus sp., Nemesia sp., and Eschscholzia californica. a-1, b-2, c-2, d-1, and e-1 show CPP appearing earlier compared to background pigmentation in Campsis radicans, Digitalis purpurea, Catharanthus roseus, Dianthus sp., and Nemesia sp. and $\mathbf{f - 1}$ shows CPP appearing after background pigmentation in Eschscholzia californica

Figure 4. Model for the early appearance of pattern pigmentation compared to the

\section{background}

Three hypotheses (not mutually exclusive), presented starting from the bottom and connected by black arrows, may in combination suggest the early development of pigment pattern observed in the study. I (bottom), Reaction-diffusion: Interactions between morphogens - an activator (e.g., hormone, TF, or miRNA) and an inhibitor - are indicated by straight arrows. Interaction of the activator with the inhibitor molecule inhibits, whereas accumulation of the activator triggers the localized expression of pigmentation. The nature of the "trigger" (red star) is unknown, but could be the activator molecule itself, and is likely set off during the cell division phase. II (middle), 
472 Differential gene expression: The trigger activates transcription factors R2R3-MYB (sub473 group 6) (yellow star, early-acting; orange star, late-acting) that differentially regulate 474 pigment-synthesizing structural genes coding for enzymes of the flavonoid biosynthetic 475 pathway, e.g., dihydroflavonol reductase (DFR); different copies of DFR are activated at 476 different times -- the early-expressing copies act in the CPP region, and the late477 expressing copies act in the background. III (top), Reaction kinetics: Early formation of 478 pigment molecules in the CPP region allows time for accumulation of greater amount 479 (quantitative) and variety (qualitative) of pigments as might be required by the reaction 480 rate kinetics of the biochemical pathway, possibly including a rate-limiting step (blue 481 star) The dashed circles indicate CPP regions; blue and purple shapes (triangle, rhombus, 482 pentagon and hexagon) represent different pigment molecules in the CPP and background 483 region. Differential expression of DFR genes and their role in pigmentation, and reaction 484 kinetics DFR gene products, is known; a role for reaction-diffusion is plausible but needs 485 to be tested. 


\section{Figures}
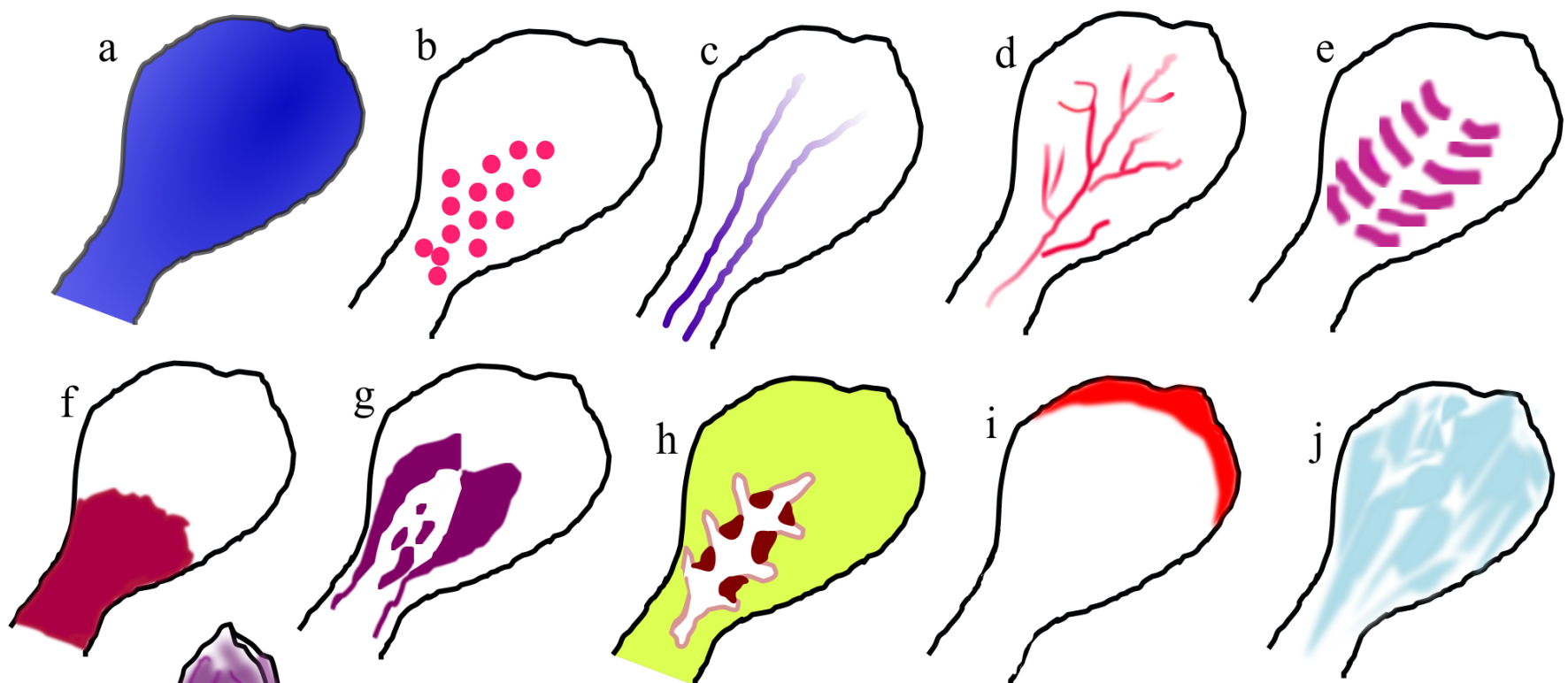

$\mathrm{k}$
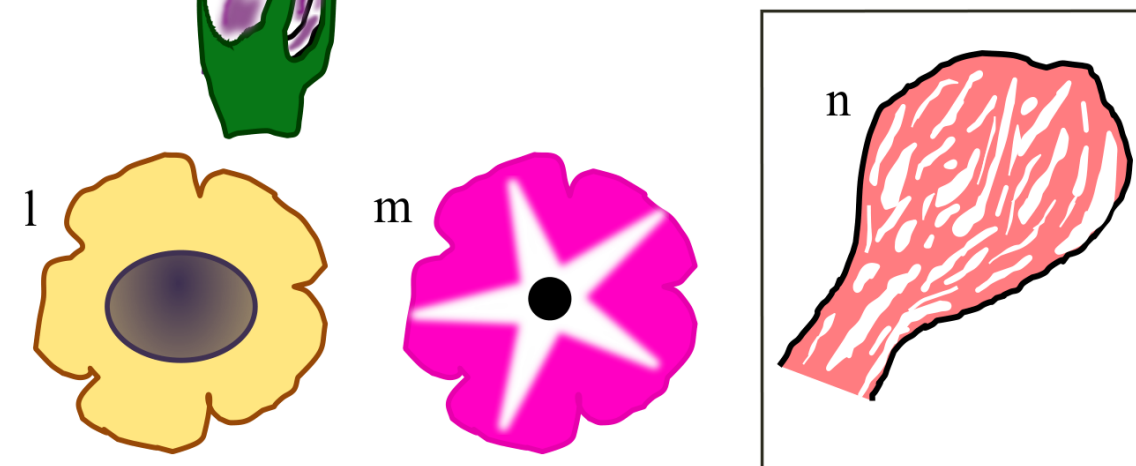

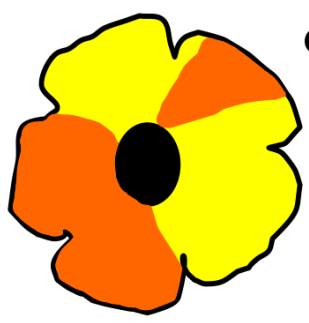

(i)

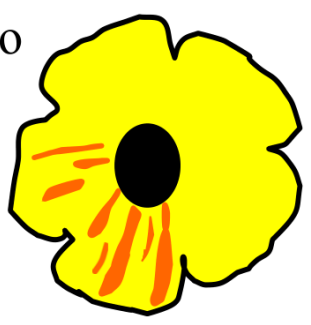

(ii)

\section{Figure 1}

Figure 1. Illustration of the different forms of corolla pigment pattern:

(a-m) stable pattern ( $\mathbf{n}, \mathbf{0})$ unstable pattern (a) background colouration (e.g. ${ }^{\Psi}$ Barleria prionitis; Acanthaceae) (b) spot pigmentation pattern (e.g. ${ }^{\Psi}$ Rhododendron triflorum; Ericaceae) (c, d) streak pattern (e.g. ${ }^{\Psi}$ Duranta erecta; Verbenaceae) (e) band pattern ( ${ }^{\Psi}$ Andrographis paniculata; Acanthaceae) (f) blotch pattern ( ${ }^{\Psi}$ Rhododendron dalhousiae; Ericaceae) $(\mathbf{g}, \mathbf{h})$ composite pattern ( ${ }^{\Psi}$ Dicliptera paniculata and $\Psi$ Justicia simplex, Acanthaceae) (i) picotee pattern [Aquilegia vulgaris; Ranunculaceae (Kristofferson 1922) and Papaver rhoeas; Papaveraceae (Newton 1929)] (j) colour tinge/flush (k) bud-blush pattern (e.g. ${ }^{\Psi}$ Allamanda blanchetii; Apocynaceae) (I) bull's-eye pattern (whole flower) [e.g. Argentina anserine (Koski

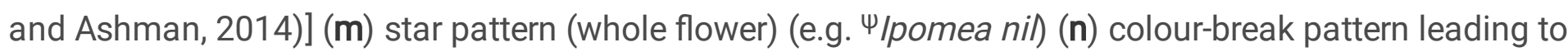
formation of bicolour flowers [e.g. in daffodils, tulips and lilies (Hunter et al. 2011)] (o-i, o-ii) chimeric pattern showing two distinct flowers from the same plant [e.g. Mirabilis jalapa; Nyctaginaceae (Demerec, 1935)] ${ }^{\Psi}$ - pers. obs. 


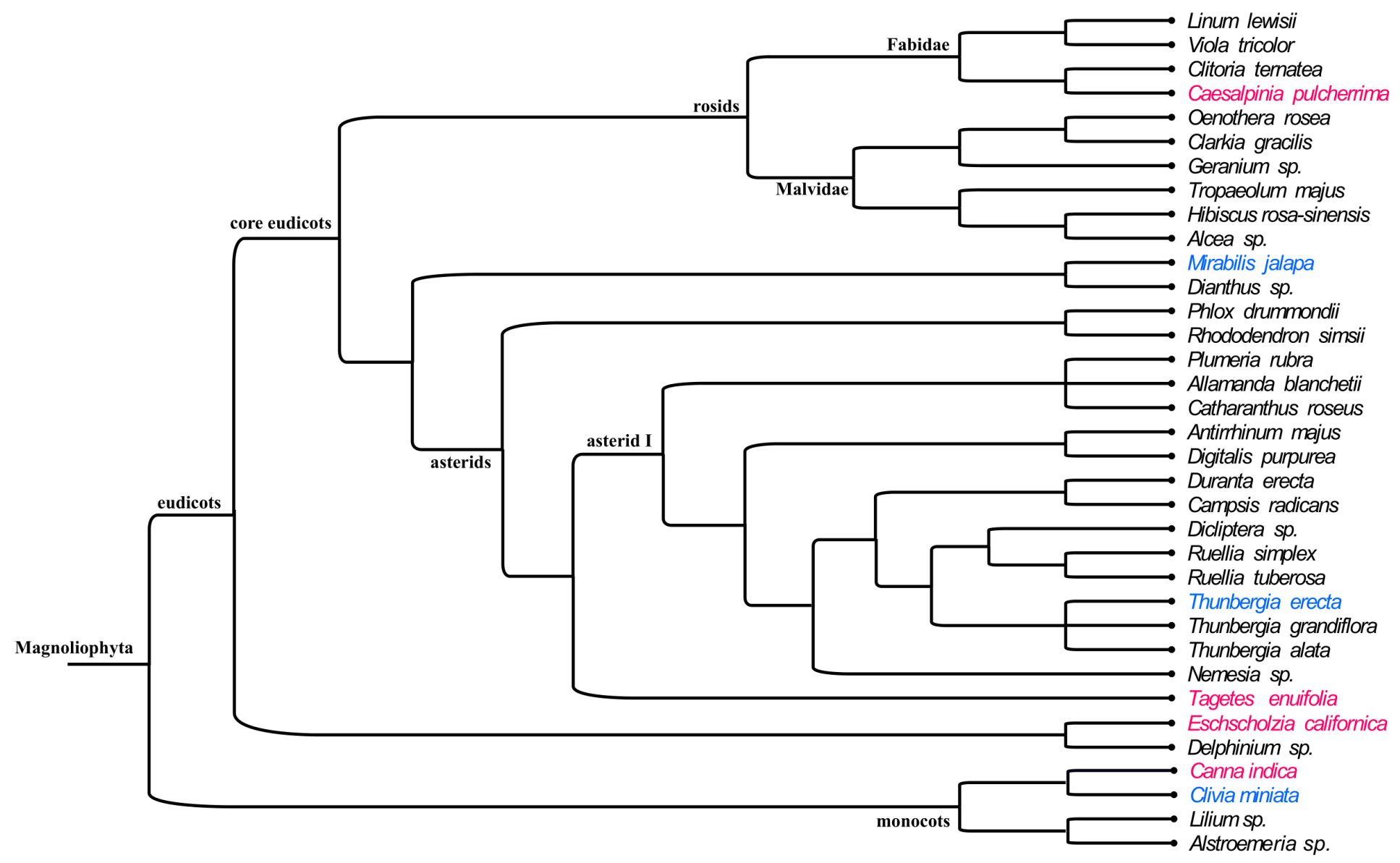

Figure 2

Figure 2. Taxa sampled

Out of the 35 species studied 28 showed CPP development starting earlier than the background pigmentation; four taxa, that are marked with pink coloured branches, showed precedence of background pigmentation over CPP; and three taxa here marked with a blue branch had CPP and background pigmentation emerging simultaneously 

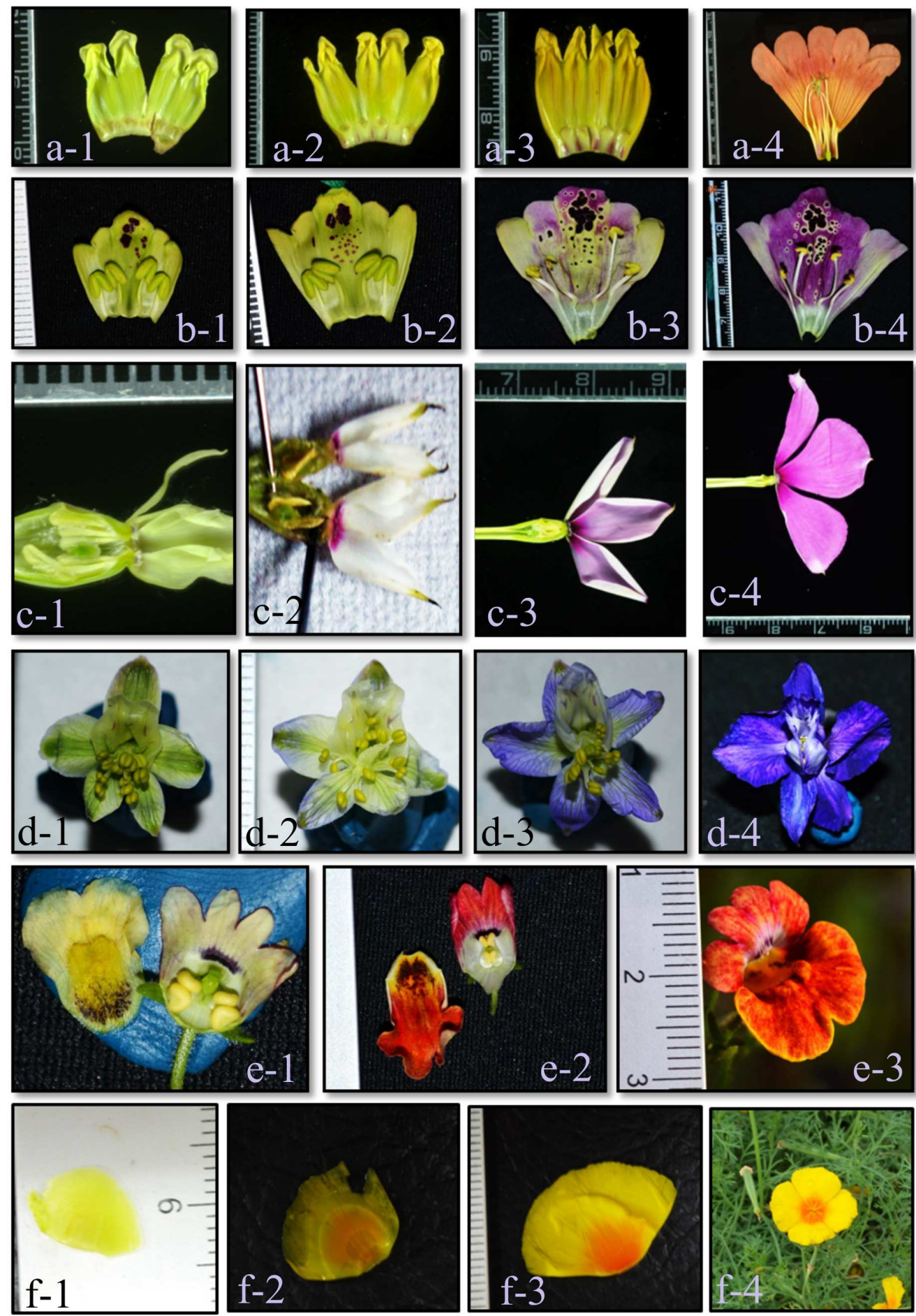

Figure 3

Figure 3. Stages in the development of CPP and background pigmentation in representative species a-f Campsis radicans, Digitalis purpurea, Catharanthus roseus, Dianthus sp., Nemesia sp., and Eschscholzia californica. a-1, b-2, c-2, d-1, and e-1 show CPP appearing earlier compared to background 
III. Reaction kinetics of anthocyanin biosynthesis pathway demands early start of synthesis in CPP region richer in pigment.

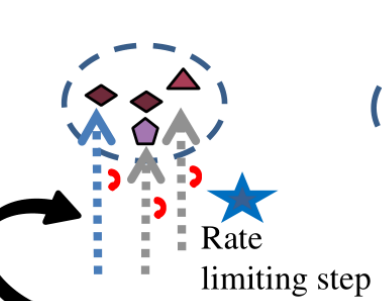

(hypothetical)

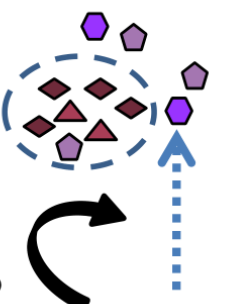

II. Early expression of structural genes, e.g. DFR genes) in CPP region causes earlier expression of pigments compared to background.

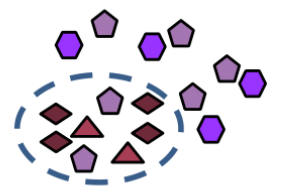

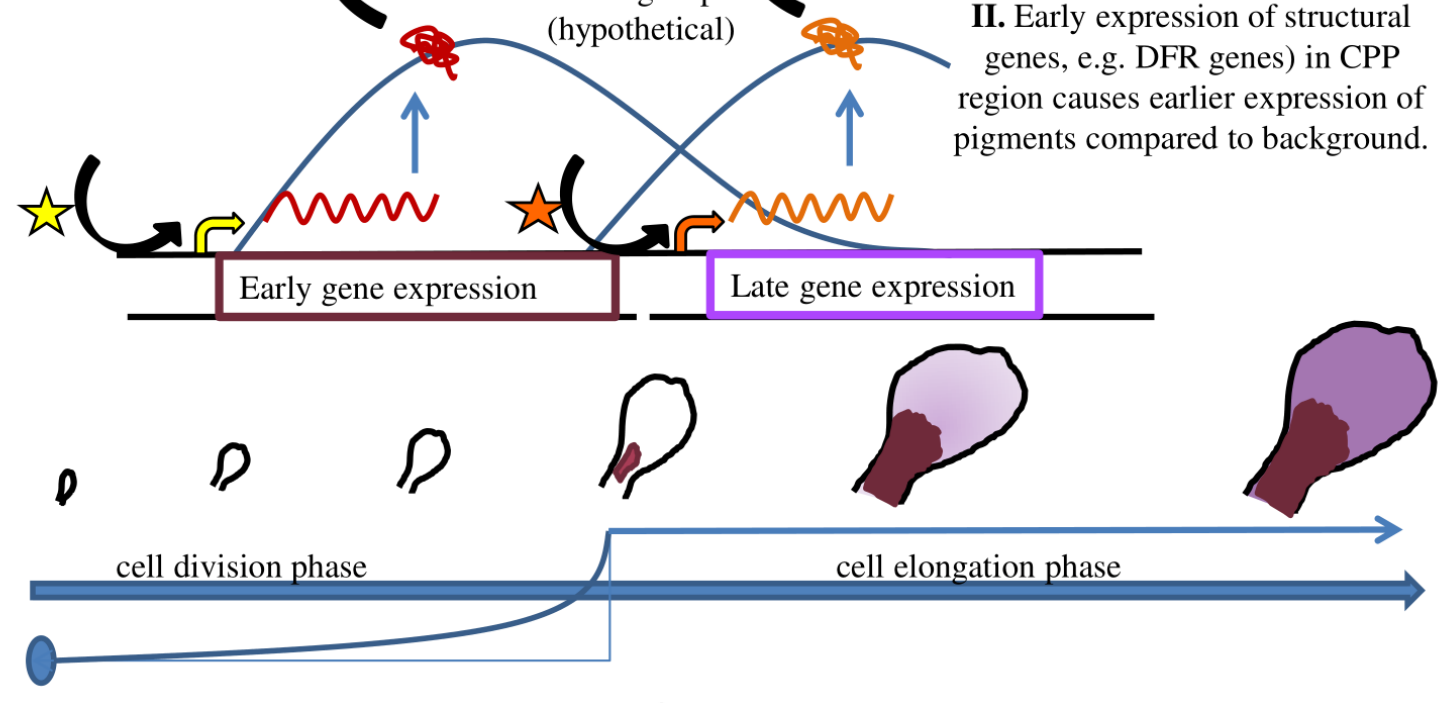

Morphogen: Activator (slow diffusing, autocatalytic)

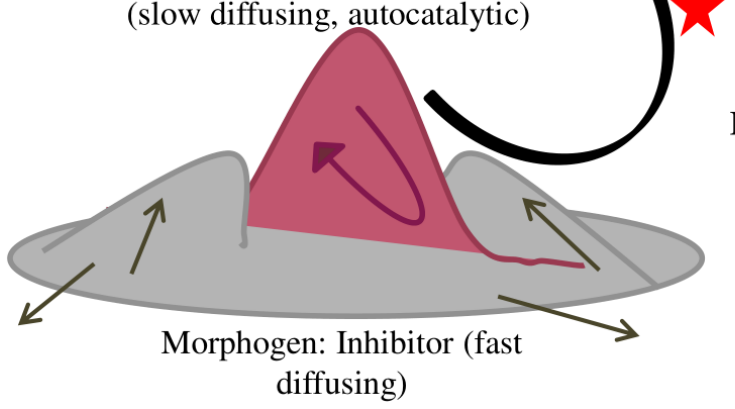

Triggers CPP

development

I. Reaction-diffusion model allows inhibition of pigmentation in background and early activation of pigmentation in CPP region. Background pigmentation is allowed after cessation of activity of inhibitor molecule.

\section{Figure 4}


Three hypotheses (not mutually exclusive), presented starting from the bottom and connected by black arrows, may in combination suggest the early development of pigment pattern observed in the study. I (bottom), Reaction-diffusion: Interactions between morphogens - an activator (e.g., hormone, TF, or miRNA) and an inhibitor - are indicated by straight arrows. Interaction of the activator with the inhibitor molecule inhibits, whereas accumulation of the activator triggers the localized expression of pigmentation. The nature of the "trigger" (red star) is unknown, but could be the activator molecule itself, and is likely set off during the cell division phase. II (middle), Differential gene expression: The trigger activates transcription factors R2R3-MYB (sub-group 6) (yellow star, early-acting; orange star, late-acting) that differentially regulate pigment-synthesizing structural genes coding for enzymes of the flavonoid biosynthetic pathway, e.g., dihydroflavonol reductase (DFR); different copies of DFR are activated at different times - the early-expressing copies act in the CPP region, and the late-expressing copies act in the background. III (top), Reaction kinetics: Early formation of pigment molecules in the CPP region allows time for accumulation of greater amount (quantitative) and variety (qualitative) of pigments as might be required by the reaction rate kinetics of the biochemical pathway, possibly including a ratelimiting step (blue star) The dashed circles indicate CPP regions; blue and purple shapes (triangle, rhombus, pentagon and hexagon) represent different pigment molecules in the CPP and background region. Differential expression of DFR genes and their role in pigmentation, and reaction kinetics DFR gene products, is known; a role for reaction-diffusion is plausible but needs to be tested.

\section{Supplementary Files}

This is a list of supplementary files associated with this preprint. Click to download.

- tables2.docx

- legends.docx

- Figures1.pdf

- FigureS2Soltistreeajb20704supAug2021.pdf

- TableS1.doc

- TableS2SCORINGSoltisAppS01.xlsx 